\title{
Preliminary Investigation of Toxoplasmosis in Selected Domestic Animals in Wondo Genet, Ethiopia
}

\author{
Eyob Eticha ${ }^{1 *}$, Gizat Almaw ${ }^{2}$, Diriba Lemma ${ }^{1}$ and Birhanu Abera \\ ${ }^{1}$ Asella Regional Veterinary Laboratory, Ethiopia \\ ${ }^{2}$ National Animal Health Diagnostic and Investigation Center, Ethiopia
}

\begin{abstract}
A cross sectional survey was conducted with the objective of determining the occurrence of Toxolasmosis in Wondo Genet, Ethiopia. The study animals were sheep, goats and chickens and a total of 96 animals were included in the study. Serum samples were collected from these animals and tested using Direct Agglutination Test (DAT) at $1: 40$ cut off point. A seroconversion rate of $48.75 \%, 75 \%$ and $12.5 \%$ was found in sheep, goats and chickens, respectively. The effect of some selected risk factors in sheep was studied and a higher occurrence was observed in older age, females and in ewes with history of abortion, neonatal mortality, or weak birth (ANW). However, this difference was found to be statistically not significant $(p>0.05)$. This study showed that there was a high occurrence of toxoplasmosis in Wondo Genet in domestic animals. Therefore, further detail investigation is needed to further understand the importance of toxoplasmosis in animal productivity and public health.
\end{abstract}

Keywords: Chicken; Direct Agglutination Test (DAT); Goat; Sheep; Toxoplasmosis; Wondo Genet

\section{Introduction}

Infections are widely prevalent in human beings and other warmblooded animals worldwide. Free-range chickens and small mammals are considered important in the life cycle of because cats preying on these infected animals can shed millions of environmentally resistant oocysts [1]. Cats and other felids are the only definitive hosts of toxoplasma on which sexual reproduction occur to produce infective Oocyst. Warm blooded animals including humans, are intermediate hosts that harbor tissue cyst in their bodies [2]. The parasite is transmitted by ingestion of Infectious Oocyst in contaminated food and water, or under cooked meat containing tissue cyst (bradyzoites), and congenitally. Transplacental Infection occurs when an infected mother acquires infection of tachyzoites during pregnancy [3]. Close proximity increase the chance of infections; studies indicated that only $2 \%$ of the sheep raised without cats had antibodies to, whereas antibodies were found $32 \%$ of the sheep raised with cats [4].

The clinical syndrome and the cause of toxoplasmosis vary a great deal between species and between age groups. In animal toxoplasmosis is of both clinical and economic importance, particularly in sheep and goats production. And also in birds clinical signs reported were anorexia, jerking of neck and head, paralysis, and loss of eye sight [1]. Toxoplasmosis in these susceptible hosts is one of the common cause of abortion, fetal mummification, resorbition, still birth, birth of live but weak offspring and early postnatal mortality [5]. In immunocompetent human beings, infection usually runs sub-clinical or asymptomatic course. However, in immunocompromised patient and congenital infected individuals it causes severe and often fatal episodes. Financial losses incurred due to toxoplasmosis are difficult to determine and data showing such financial figures are scanty [6]. Indicated a financial loss amounting to USD 1.4-4.7 million in sheep flock in Uruguay due to infection with Another study has revealed that toxoplasmosis cause an annual economic /public health burden amounting to USD 400 million. Murell estimated financial losses associated with congenital toxoplasmosis to be as high as USD 430 million [7]. The financial losses incurred due to this parasite would have been grater if the economic losses due to handling of mentally retarded children loss of vision and other human sufferings and management costs are included [2].

Diagnosis of toxoplasmosis can be achieved by either direct demonstration of the agent in the tissues or body fluid of infected host or indirectly by detection of anti-toxoplasma antibodies in serum from infected individuals [8]. Serological methods of diagnosis have been established and used since mid-1930s, most of these serological techniques have been widely applied for epidemiological studies of toxoplasmosis worldwide [9].

The estimated world wild seroprevalence of toxoplasmosis in livestock is; cattle $9 \%$, sheep $30 \%$ and goats $15 \%$ [10]. According to Tenter et al. [11] Worldwide serum prevalence of caprine toxoplamosis during 1990-1999 ranged from 0\% in Pakistan to 77\% in France more recently prevalence of $12.3 \%$ was observed in Sardinia, Italy Masala et al. [5] 30\% in Iran, Sharif et al. [10] and 74.8\% in Ethiopia [12]. There have been also several serological survey for antibodies to in small ruminants in different part of Ethiopia by Tameru, Tilaye and Getachew [13,14]. With seroprevalence rate of $22.9 \%, 54.7 \%$, and $34 \%$ in sheep and $11.9 \%, 26.7 \%$ and $33 \%$ in goats respectively. In serological survey in Israel in chicken $46.6 \%$ was reported [2].

There is no information on the prevalence of toxoplasma infection in Wondo Genet, Ethiopia. The present study was therefore, undertaken to estimate the prevalence of the antibodies in sheep, goats and chicken and its association with some risk factors.

*Corresponding author: Eyob Eticha, Asella Regional Veterinary Laboratory PO Box 212, Ethiopia, Tel: +251913178237; Fax: +2510223313426; E-mail: eyoba20000@gmail.com

Received December 09, 2016; Accepted January 19, 2017; Published January 21, 2017

Citation: Eticha E, Almaw G, Lemma D, Abera B (2017) Preliminary Investigation of Toxoplasmosis in Selected Domestic Animals in Wondo Genet, Ethiopia. J Vet Sci Technol 8: 416. doi: 10.4172/2157-7579.1000416

Copyright: (C) 2017 Eticha E, et al. This is an open-access article distributed under the terms of the Creative Commons Attribution License, which permits unrestricted use, distribution, and reproduction in any medium, provided the original author and source are credited. 


\section{Materials and Methods}

\section{Study animals}

The study animals were sheep, goats and chickens. These animals were owned by farmers of Gotuo-Onema and Kella villages of Wondo Genet. And regarding the herd size these farmers own from 1 to 17 heads of sheep and 1 to 16 heads of goat (herd size). All animals were indigenous local breeds of different sex and age. The management system was extensive and semi-intensive. And for the purpose of this study animals which were dependent only on grazing were categorized under extensive and in the semi-intensive category were herd sizes of 16 and above and kept for most of the time indoor with supplement provision. Data on age, sex, presence of cat, abortion or neonatal mortality or weak births and management was collected on a pretested questionnaire. But statistical test was conducted only on data obtained from sheep as small number of samples was tested for other study animals. Sheep and goats of above 1 year of age were included in the study to avoid measuring antibodies passively transferred in colostrums.

\section{Study area}

The study was conducted from November 2008 to April 2009 in Wondo Genet, Ethiopia. Located at $7^{\circ} 6 \mathrm{~N}$ latitude and $38^{\circ} 7^{\circ} \mathrm{E}$ longitude, $270 \mathrm{~km}$ to the south of Addis Ababa at an altitude of about 1800 meters above sea level. Wondo Genet has a bimodal rainfall distribution, with two rainy seasons. A minor rainfall period occurs in February to April and more extensive in July to September. The annual average rainfall is $1200 \mathrm{~mm}$, but varies between 700 and $1400 \mathrm{~mm}$.

\section{Study design}

Cross-sectional study: The study was a cross-sectional one where each animal was sampled only once during the study period and was conducted from November 2008 to April 2009 to determine the occurrence of toxoplasmosis in sheep, goats and chickens.

Sample size determination and study animal selection: A total of 96 animals were included in the study and selection was performed randomly from group of animals in the study village. Ninety six were collected and of these 80,8 and 8 were obtained from sheep, goats and chickens, respectively. All the samples were tested by Direct Agglutination Test (DAT) (REF 75481 TOXO-Screen DA).

\section{Sample Collection}

\section{Serum samples}

Approximately $5 \mathrm{ml}$ of blood from jugular vein of sheep and goats was collected aseptically using sterile plain vacutainer tubes and needles. Chickens were killed by cervical dislocation and blood was obtained from the heart. The samples were properly labeled; the tubes were left at slant position for 8 hours at room temperature to allow clotting and the sera separated. The sera were then transferred to another sterile vial and kept at $-20^{\circ} \mathrm{C}$ until tested.

\section{Diagnostic Methods}

The serological test was carried out at the National Veterinary Institute (NVI), Debre Zeit, Ethiopia using Direct Agglutination Test (DAT). This test kit detects toxoplasma antibodies and is produced by BioMerieux, France. IgM-mediated agglutination is suppressed by using a diluting buffer containing 2-mercaptoethanol. The assay was supplied as a kit containing $4 \mathrm{ml}$ of a suspension of treated with formalin and obtained from mouse ascitic fluid, $16 \mathrm{ml}$ of diluent (BABScolour buffer), $1 \mathrm{ml}$ of concentrated 2-mercaptoethanol which was diluted to give a $0-2 \mathrm{~mol} / \mathrm{l}$ solution, lyophilised positive and negative control sera (each to be diluted to $1 \mathrm{ml}$ ) and powdered phosphate buffered saline (PBS) to be diluted to one liter. Four microtitration plates, four self-adhesive plate covering sheets and four report sheets were also included in the kit. A serum sample showing agglutination reaction manifested by precipitation with irregular edges at the butt of the well at 1:40 titer was considered positive following the manufacturer's recommendation.

\section{Data Analysis}

For quantification of toxoplasmosis proportion was used for all animals. Univariate logistic regression was employed for data obtained from sheep to analyze the association of selected risk factor with the occurrence of Toxoplasmosis.

\section{Results}

The result is presented as proportion instead of prevalence since few sera were tested. Although the sample size and sampling strategy was conducted following relevant statistical methods it was not possible to make an inference to the study population because of small number sample size.

\section{Overall proportion ('prevalence')}

Anti-toxoplasma antibody titer ranging from 1:40 to 1:4000 was detected in sheep, goats and chicken serums examined for antitoxoplasma antibodies using DAT. An overall seroconversion rate of $47.91 \%$ was observed in the tested sample and of this $48.75 \%, 75 \%$ and $12.5 \%$ were found in sheep, goats and chickens, respectively (Table 1). Of the 39 positive sheep serum sample, $16(20 \%)$ were positive only at $1 / 40$ and the remaining $23(28.75 \%)$ were positive both at dilution of $1 / 40$ and a greater or equal to $1 / 4000$. The corresponding number of goat sera were $1(12.5 \%)$ and $5(62.5 \%)$. From chicken only one bird was found positive and the serum sample was positive at 1:40 and 1:4000 dilutions.

The occurrence of toxoplasomis in sheep was also summarized by selected risk factors (Table 2). A progressive increase in the rate of occurrence of toxoplasmosis with age was noticed. The age specific proportion was $41.7 \%$ at $1-3$ years old and $59.37 \%$ for more than 3 years old indicating the occurrence was high in older ages. The sex specific occurrence was high in females or ewes (49.2\%) compared to males or rams (46.6\%). A very high occurrence was observed (83.3\%) in ewes with abortion, neonatal mortality, or weak birth (ANW) compared to ewes not having these problems (42.64\%). A result opposite to our hypothesis was observed regarding toxoplasmosis occurrence in sheep in the absence and presence of the definitive host, cat. The occurrence was high $(52.63 \%)$ in the absence of cat in comparison to their presence (39.13\%) (Table 2). However, these differences in occurrence of toxoplasmosis by different risk factors were not found to be statistically significant in univariate logistic regression $(\mathrm{p}>0.05)$.

\section{Discussion}

The overall seroprevalence of $48.75 \%$ recorded in sheep in present study is higher than those reported earlier from different areas of Ethiopia. But this finding was closer to Tamiru work in Nazareth Ethiopia [14]. It is difficult to determine the overall prevalence of goats and chicken in the present study because of less number of the sample size. However, $75 \%$ in goats and $12.5 \%$ in chicken occurrence 


\begin{tabular}{|c|c|c|c|}
\hline Animals & Number tested & Number positive & Proportion (\%) \\
\hline Sheep & 80 & 69 & 48.75 \\
\hline Goats & 8 & 1 & 75 \\
\hline Chickens & 8 & 46 & 12.5 \\
\hline Total & 96 & 47.91 \\
\hline
\end{tabular}

Table 1: Occurrence of $T$. gondii using DAT in selected domestic animal.

\begin{tabular}{|c|c|c|c|c|c|c|c|c|c|c|}
\hline \multirow{2}{*}{ Description } & \multicolumn{2}{|c|}{ Age } & \multicolumn{2}{|c|}{ Sex } & \multicolumn{2}{|c|}{ ANW $^{a}$} & \multicolumn{2}{|c|}{ Cat } & \multicolumn{2}{|c|}{ Management } \\
\hline & $1-3$ years & $>3$ years & $\mathrm{F}$ & M & present & absent & presence & absent & Extensive & Semi-intensive \\
\hline No. examined & 48 & 32 & 65 & 15 & 12 & 68 & 23 & 57 & 66 & 14 \\
\hline No. positive & 20 & 19 & 32 & 7 & 10 & 29 & 9 & 30 & 34 & 5 \\
\hline Proportion & 41.7 & 59.37 & 49.23 & 46.7 & 83.3 & 42.64 & 39.13 & 52.63 & 51.51 & 35.71 \\
\hline
\end{tabular}

aAbortion Neonatal Mortality or Weak birth

Table 2: Occurrence of $T$. gondii using DAT in sheep by risk factors.

in this study was indicative of the existence of the problem in these animals and the result of this work can further confirm the presence of these animals in Ethiopia. The difference in seroprevalence of toxoplasma infection in sheep and goats between the present work and the previous report from Ethiopia may be attributed to different in localities. Toxoplasma seroprevalence is highly variable in different eco-geographical areas; higher prevalence being observed in warm and moist areas than cold or hot dry areas. Apart from difference in localities, variation may be also reported to the diagnostic methods (in the present study DAT was used whereas in previous studies modified direct agglutination test (MAT) was employed), sampling method, age of the animal sampled and husbandry practices used. The relative cat density in the area and the access of the cat to contamination feed and water Oocyst should also be considered although the present finding was a high occurrence in cat's absence. This difference could be as a result of other risk factors which might undermine the cat's role in the area including erosion and presence of wild cats.

The seroprevalence increase with increasing age (43.75 and 59.2) in sheep among the two age-groups (1-3 and $>3$ ) in the present study was also observed in previous study at Debre Berhan, Ethiopia [14]. The age related difference in acquisition of infection is expected because older animals have a higher chance of exposure to oocyst compared to younger animals. The difference in sex-specific prevalence rate (high in ewes) observed in this study in sheep is in agreement with previous reports. And this sex difference could be attributed to difference in the management system where rams were sold early and have a high turnover compared to ewes where ewes would be maintained for longer periods for reproductive purpose and the chance of exposure for the disease would increase.

\section{Conclusion and Recommendation}

In this cross-sectional investigation it was found that toxoplasmosis was prevalent $(47.91 \%)$ in the tested domestic animals. Its occurrence in sheep, goats, and chicken was $48.75 \%, 75 \%$ and $12.5 \%$ respectively. A higher occurrence was observed in older age, females and ewes with a history of abortion, neonatal mortality, or weak birth (ANW). However, this difference was found to be statistically not significant $(\mathrm{p}>0.05)$.

Based on this finding the following recommendation are forwarded.

- Improvement of hygienic practice and management can reduce the incidence of toxoplasma both in animal and humans.

- The economic and public health impact of, needed to be assessed thoroughly throughout Ethiopia.
- An investigation should be undertaken to identify other possible causes of abortion in sheep.

\section{Acknowledgements}

Authors special thank goes to all the staff member of Aklilu Lemma Institute of Pathobiology esp. to Professor Getachew Tilahun for the provision of test kits and his valuable advice, National veterinary Institute and Gondar university, faculty of veterinary medicine have played a role for the success of this work.

\section{References}

1. Dubey JP, Webb DM, Sundar N, Velmurugan GV, Bandini LA, et al. (2007) Endemic avian toxoplasmosis on a farm in Illinois: clinical disease, diagnosis biologic and genetic characteristics of Toxoplasma gondii isolates from chickens (Gallus domesticus), and a goose (Anser anser). Vet Parasitol. 148: 207-212.

2. Dubey JP, Salant H, Sreekumar C, Dahl E, Vianna MC, et al. (2004) High prevalence of Toxoplasma gondii in a commercial flock of chickens in Israel, and public health implications of free-range farming. Vet Parasitol. 121: 317322.

3. Singh S (2003) Mother to child transmission and diagnosis of Toxoplasma gondii infection during pregnancy. Ind J Med Microbiol. 21: 69-76.

4. Acha PN, Szyfres B (2003) Zoonoses and Communicable Diseases Common to Man and Animals. Parasitic Zoonoses. Pan American Health Org. 76-86.

5. Masala G, Porcu R, Madau L, Tanda A, Ibba B, et al. (2003) Survey of ovine and caprine toxoplasmosis by IFAT and PCR assays in Sardinia, Italy. Vet Parasitol. 117: 15-21.

6. Freyre A, Bonino J, Falcon J, Castells D, Correa O, et al. (1999) The incidence and economic significance of ovine toxoplasmosis in Uruguay. Vet Parasitol. 81: 85-87.

7. Murell KD (1991) Economic losses resulting from food-born parasitic zoonoses South East Asian J Trop Med Public Health. 22: 377-381.

8. Hill DE, Chirukandoth S, Dubey JP, Lunney JK, Gamble HR (2006) Comparison of detection methods for Toxoplasma gondii in naturally and experimentally infected swine. Vet Parasitol 141: 9-17.

9. Gamble HR, Dubey JP, Lambillotte DN (2005) Comparison of a commercial ELISA with the modified agglutination test for detection of Toxoplasma infection in the domestic pig. Vet Parasitol. 128: 177-181.

10. Sharif M, Gholami SH, Ziaei H, Daryani A, Laktarashi B, et al. (2007) Seroprevalence of Toxoplasma gondii in cattle, sheep and goats slaughtered for food in Mazandaran province, Iran, during 2005. Vet J 174: 422-424.

11. Tenter AM, Heckeroth AR, Weiss LM (2000) Toxoplasma gondii from animal to humans. Int J Parasitol. 30: 1217-1258.

12. Carnew C, Carnerio ACV, Goveia M (2009) Seroprevalence and risk factor of caprine toxoplasimosis in Mices Gerals, Brazil. Vet Parasitol 160: 225-229.

13. Tilaye D, Getachew T (2002) Study on toxoplasmosis in sheep and goats in Debre Birhan and surrounding areas in Ethiopia. Bull Anim Heal Prod Afr. 50:138-147.

14. Tamiru N (2000) Study on Toxoplasimosis. DVM Thesis, Faculty of Veterinary Medicine, Addis Ababa University, Debere Zeit, Ethiopia. 